\title{
Refractory Ewing Sarcoma/Peripheral Primitive Neuroectodermal Tumor
}

National Cancer Institute

\section{Source}

National Cancer Institute. Refractory Ewing Sarcoma/Peripheral Primitive

Neuroectodermal Tumor. NCl Thesaurus. Code C153286.

A malignant small round cell tumor with or without neural differentiation that is resistant to treatment. 